\title{
A ambivalência do protesto no teatro e na canção no Brasil pós-1964
}

\author{
The ambivalence of protest in theater and music \\ in post-1964 Brazil \\ Paulo Bio Toledo
}

Paulo Bio Toledo Mestre e doutorando pelo PPGAC da ECA-USP

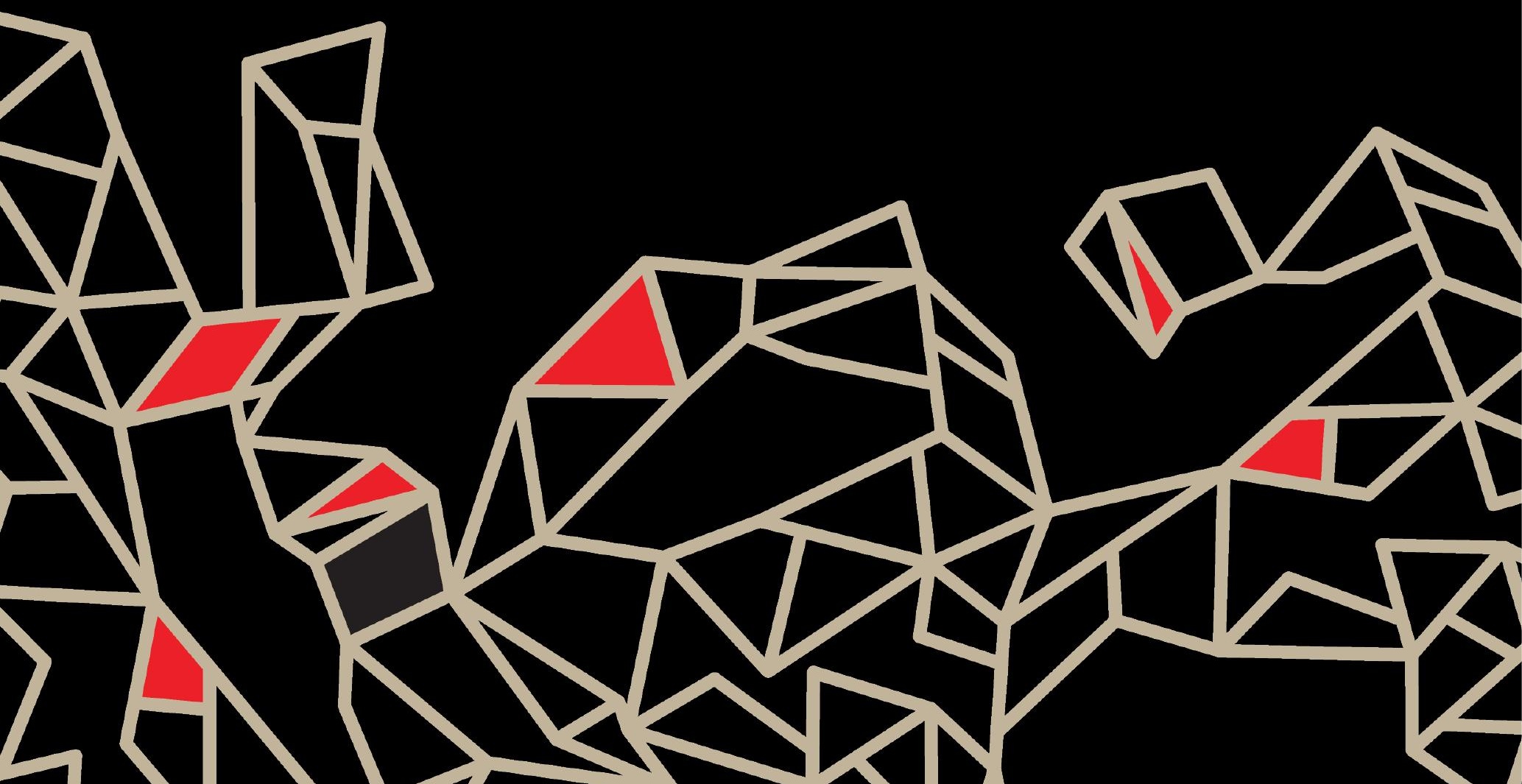




\section{Resumo}

Nos primeiros anos após o Golpe Militar de 1964, o teatro e a canção viveram dilemas centrais para seu desenvolvimento. De um lado estava a tentativa de resistir esteticamente ao arbítrio e a interrupção das experiências populares do período anterior; de outro, o entusiasmo com o sucesso da nova produção e com o alcance da indústria de massa. $\mathrm{O}$ artigo discute estas questões no texto e nas canções do espetáculo Arena conta Zumbi, de Augusto Boal e Gianfrancesco Guarnieri, bem como na releitura de Maria Bethânia em 1965 para Vivo num tempo de guerra, canção-chave do espetáculo e emblemática para o período. Por fim, analisa a crítica de Boal à cultura de esquerda pós-1964 no programa da / Feira Paulista de Opinião.

Palavras-chave: Teatro de Arena, Canção de protesto, Augusto Boal.

\section{Abstract}

In the early years after the Brazilian military coup of 1964, theater and music experienced central dilemmas to their development. On one hand, there was the attempt to aesthetically resist the arbitrariness and the interruption of popular experiences of the previous period, on the other hand, the enthusiasm with the success of new production, and the extent of mass industry. The article discusses these issues in the text and songs of theatre play Arena conta Zumbi, from Augusto Boal and Gianfrancesco Guarnieri, as well as in Maria Bethania's replay of Vivo num tempo de guerra, in 1965, a key song of the theater play and emblematic for the period. Finally, it analyzes Boal's critics of the left-wing culture post-1964 in the program of I Feira Paulista de Opinião.

Keywords: Teatro de Arena, Protest song, Augusto Boal.

Logo após os tanques e fuzis tomarem conta da arena política no Brasil, o teatro e a canção protagonizaram uma das mais imediatas respostas no campo da cultura. O Show Opinião, no Rio de Janeiro, dirigido por Augusto Boal ainda em 1964 (e produzido por grupo liderado por Vianinha, Armando Costa, Paulo Pontes, Ferreira Gullar e João das Neves), foi o primeiro gesto de resistência ao reunir artistas ligados às tentativas de popularização da arte no período anterior e músicos de vários estratos sociais para cantar: "podem 
me prender/podem me bater/ que eu não mudo de opinião" (COSTA et al., 1965). O diretor parece ter percebido ali um fértil caminho de resistência para o teatro, afinal o sucesso do show fora enorme e agremiara toda uma fração social inconformada com o andamento da política. Seguindo essa trilha é que Boal, de volta ao Teatro de Arena de São Paulo, Gianfrancesco Guarnieri e Edu Lobo escrevem e organizam Arena Conta Zumbi, um dos mais importantes acontecimentos teatrais do período.

O musical estreou no dia $1^{\circ}$ de maio de 1965 , exatos um ano e um mês depois do Golpe de Estado de 1964. A história da luta do Quilombo de Palmares foi matéria-prima para uma tomada de posição ainda mais enfática diante da inflexão ditatorial nos rumos do país. Com uma cena dinâmica e surpreendente, Arena conta Zumbi inaugurou uma série de novidades estéticas no campo do teatro engajado do período e marcou toda uma geração com seu espírito de resistência. A história era narrada e cantada por um coro, sem protagonismos. As figuras históricas representadas na peça eram interpretadas por vários atores diferentes, num primeiro esboço daquilo que Boal teorizaria, em 1967, como o Sistema Coringa (BOAL, 1975). Trata-se de um método de representação em que não eram as particularidades históricas do fato que ficavam em primeiro plano, mas a ação de contar este fato em cena; e isso, nas palavras de Boal: "de uma perspectiva terrena bem localizada no tempo e no espaço: a perspectiva do Teatro de Arena, e de seus integrantes" (BOAL, 1975, p. 184).

Zumbi não era uma peça histórica sobre o quilombo e suas particularidades; era, antes, um musical do tempo presente, em que atores do Teatro de Arena contavam, em 1965, a história de Palmares. Para isso, apoiavam-se numa organização nova do teatro: o jogo coral entre os atores, a característica épica do texto e do espetáculo, a narrativa, o comentário, a relação de cumplicidade com o público, as constantes referências satíricas à política do momento criavam uma cena de grande força circunstancial. A nova estrutura neutralizava o enlevo do teatro dramático (que tanto entusiasmara os artistas do Teatro de Arena entre 1958 e 1964) e propunha uma relação direta e objetiva para com o público, que era, afinal, o objeto indireto implícito do verbo "contar" empregado no título. Desde o início ficava deflagrada a operação de transformar a particularidade histórica em comentário presente e transformar o teatro numa ágora de debate envolvendo o público e o grupo. Com efeito, mais do que simples atualização temática, a presentificação do objeto histórico, neste caso, se realiza 
numa relação cênica épica e experimental, que fazia do momento da apresentação a sua força, um grande achado para o teatro do período.

As canções de Edu Lobo para o espetáculo sublinham este anacronismo crítico. Não por acaso, algumas das canções foram elevadas à categoria de hinos de uma época e tiveram consequências e reverberações para além da peça. Vivo num tempo de guerra foi uma das mais emblemáticas do espetáculo e do período. Com letra inspirada no poema de Bertolt Brecht An die Nachgeborenen (Aos que vão nascer), a canção era desempenhada nos momentos finais de Arena conta Zumbi, pouco antes de Zambi, rei de Palmares, trespassar um punhal em seu próprio peito. Na cena, antes de tirar a vida, Zambi outorga a liderança do quilombo ao seu bisneto Ganga Zumba, que comandaria a última resistência de Palmares. A canção compõe um rito de passagem na peça, que, como tal, é ao mesmo tempo morte e (re)nascimento: morte de Zambi e coroação/nascimento de Ganga Zumba. A simbologia da cena ultrapassava a narrativa histórica e funcionava como uma espécie de afirmação política naquele momento imediatamente posterior ao golpe militar no Brasil. A canção, por sua vez, fazia a ponte entre os tempos. Com andamento acelerado, densidade sonora crescente e entrada de coros no refrão que mais parecem réplicas de guerreiros respondendo ao chamado de luta, a composição de Edu Lobo ao mesmo tempo em que figurava o derradeiro grito de guerra em Palmares era também um enfático hino de resistência aos militares no poder. O famoso refrão, "é um tempo de guerra/é um tempo sem sol", cantado em coro, era prontamente interpretado como diagnóstico da história interrompida em 1964, em um gesto que era ao mesmo tempo percepção do fracasso e conclamação da vitória.

Diante da canção, a sensação de reviravolta iminente enchia de esperança aqueles que se erguiam contra a ditadura recém-instituída. $O$ desencanto, a tristeza diante da derrota, o tempo digno de dó, os tanques nas ruas do país ou mesmo Palmares e seus negros aniquilados desapareceram dos cálculos ou se transformaram apenas em combustível para exaltação da luta, que se projeta em explosões cada vez mais enfáticas do coro bradando o refrão. A composição de Edu Lobo colocava os espectadores/ouvintes às vésperas da batalha final, na qual se conjugaria de vez o futuro no presente. Apesar do "sem sol" caracterizando os tempos, a estrutura da canção é solar.

Este gesto ambivalente marca o espetáculo como um todo, que terminava, por exemplo, com os atores de joelhos no palco, negros derrotados 
em Palmares, mas com os punhos erguidos, prontos pra luta. E as canções do musical reafirmavam, uma por uma, o procedimento paradoxal. Em Zambi morreu, que é cantada em seguida, o par derrota/resistência é a força do refrão: "Zambi morreu/ mas vai voltar/ em cada negrinho que chorar", bem como na canção $O$ açoite bateu, cantada logo após o assassinato de Ganga Zona, cujo refrão reaparece no último momento do espetáculo: "O açoite bateu, o açoite ensinou/ bateu tantas vezes que a gente cansou". A canção Zambi, de Edu Lobo e Vinicius de Moraes, que foi o mote para criação do espetáculo, também tem algo dessa potência nascida da tragédia: "É Zambi morrendo, ei, ei é Zambi [...] Ganga Zumba, ei, ei, vem aí/ Ganga Zumba, tui, tui, tui, é Zumbi".

Em síntese, Arena conta Zumbi apresentava a história do maior quilombo que já se viu no país como parte de uma "luta que vence os tempos" (BOAL; GUARNIERI, 1970). Durante a trama via-se o companheirismo e a consciência dos quilombolas como tradição de luta a se conectar. O entusiasmo da peça estava nessa organização em coro que olhava para os negros revoltosos de outrora e dizia: nós somos eles, eles são nós. Enquanto que, de outro lado, brancos exploradores, violentos, autoritários e comensais do capital, em tudo se assemelhavam aos militares que tomavam o poder.

Naquele primeiro momento pós-golpe, Boal foi um entusiasta desse caminho que nomeará mais tarde de "tendência exortativa" (BOAL, 1968). Bem ou mal, este espírito orientou as peças que dirigiu e/ou escreveu até 1968 no Teatro de Arena (fundamentalmente, Tempo de guerra e Arena conta Bahia, de 1965 e Arena conta Tiradentes, de 1967). Ele sabia com quem estava falando, sabia que seu público era constituído por certa juventude universitária inconformada com os rumos da política, além de setores médios progressistas da sociedade. A tentativa defendida pelo diretor era conscientemente a de realizar um "gesto didático" que estabelecesse a união entre palco e plateia na resistência possível. De fato, essa primeira produção cultural no teatro pós-golpe (como também na canção, no cinema, na literatura) marcada pela exortação de uma fração social específica, ajudou a organizar em torno de si uma mentalidade que recusava a regressão ditatorial. Salvo engano, estes gestos de resistência no campo da arte tiveram participação central na organização de um novo e significativo corpo social, segundo Roberto Schwarz (2008), "capaz de dar força material à ideologia" (p. 72), fundamentalmente estudantil, crítico e disposto a sair às ruas (como de fato saíram). E o que 
pareceu, no início, mero devaneio de classe foi ganhando força real nos anos subsequentes, a ponto de assustar os generais.

Assim, o espírito de conclamação que animava Zumbi recusou a melancolia da derrota e tentava saltar de volta à luta. Decerto fomentou o novo coro de contestação que se formava e, ao mesmo tempo, servia de estímulo e combustível para essa "nova massa". Os espetáculos e, fundamentalmente, as canções ligadas a este ambiente de inconformismo, conquistavam alcance e reverberações impressionantes.

Contudo, observando os fatos com maior distância história, vemos que a força estética do grito de resistência lidava mal com a realidade da derrota. Tanto os negros de outrora quanto a esquerda pré-1964 tinham assistido ao fracasso e à interrupção violenta de seus sonhos. O otimismo no desenvolvimento da luta, a despeito da fragorosa derrota de 1964, alimentava quimeras e se desdobrava na sensação de que as peças e as canções produzidas no período eram claros avanços estéticos e políticos quando comparados ao momento anterior, o que significava, no limite, acreditar que nada foi perdido com a inflexão de 1964 (ou, pior, que existiram ganhos). Guarnieri, numa entrevista anos mais tarde, relembra o ambiente da montagem da peça e diz: "a gente sentia necessidade de romper com o que fazia antes [...] era uma época de euforia e alegria mesmo" (GUARNIERI apud CAMPOS, 1988, pp. 9-10). Um tipo de formulação que, diga-se de passagem, não foi privilégio de um ou de outro, mas regra no campo da "cultura de esquerda" pós-19641. Para um leigo em nossa história, diante deste tipo de colocação, deve ser difícil acreditar que o país vivia uma ditadura violenta e que no primeiro dia de Golpe as grandes experiências culturais de popularização, como o Centro Popular de Cultura (CPC) e o Movimento de Cultura Popular (MCP) de Pernambuco (nas quais, bem ou mal, participaram estes mesmos artistas) foram duramente reprimidas e interrompidas.

A verdade é que sobrou muito pouco daquele momento pré-1964 em que, segundo o crítico Roberto Schwarz (2008), "a produção intelectual começava a reorientar sua relação com as massas" (p. 81), experiências que tentaram desenvolver, no limite dos projetos, o direito de que todos - sobretudo os mais pobres - tivessem direito de produzir cultura, não apenas de consumi-la. Os militares não foram nada tolerantes com as incipientes experiências de con-

1. A posição de Vianinha pós-golpe talvez seja a mais representativa deste tipo de pensamento. Cf. TOLEDO, 2013. 
trole do aparelho produtivo ou de contato vivo com as classes desfavorecidas no trabalho cultural. O CPC e O MCP foram interrompidos à força nas primeiras horas da ditadura. Não obstante, os artistas engajados nos círculos do inconformismo de classe média pós-golpe, como o Teatro de Arena, puderam seguir produzindo espetáculos nos quais "davam-se combates imaginários e vibrantes à desigualdade, à ditadura" e onde "não comparecia a sombra de um operário" (SCHWARZ, 2008, p. 94).

Mesmo sendo correto dizer que o entusiasmo presente em espetáculos como Zumbi ou em canções específicas como Vivo num tempo de guerra foi uma maneira de enfrentar o desencanto e a melancolia da derrota, de marcar posição no campo da resistência, também é verdade que havia certo entusiasmo a despeito da derrota. Nas palavras de Iná Camargo Costa (1996), foi como se o Golpe de 1964 "não passasse de um acidente de percurso, a ser removido sem maiores dificuldades" (p. 102), ou, pior, como se tivesse libertado a consciência de esquerda da precariedade produtiva e de supostos mitos e demagogias nocivas à verdadeira arte.

As contradições oriundas daí se esparramam no período entre 1965 e 1968. Arena conta Tiradentes, de 1967, escrita por Boal e Guarnieri, torna-as ainda mais graves quando, por exemplo, resolve criticar o suposto voluntarismo de elite que teria regido a luta política e cultural entre 1960 e 1964, ou quando a peça tenta retomar algo da empatia dramática do naturalismo crítico. Boa parte da canção do período, que fora o elemento forte do primeiro teatro pós-1964, também passa a desenvolver-se autonomamente, dentro de uma categoria estranha e paradoxal chamada de canção de protesto, que ao mesmo que mostra a força e o alcance da fração social resistente à ditadura, vem para atender a um novo segmento de mercado ávido por consumir souvenirs da revolução que não aconteceu.

A versão de Maria Bethânia para a canção de Zumbi, vivo num tempo de guerra, gravada ainda em 1965 no segundo compacto da intérprete, é uma significativa imagem deste processo. A organização diversa da letra na versão de Bethânia retira toda referência à Zambi, Ganga Zumba ou a luta de Palmares e lida com o material apenas pelo ângulo do comentário geral sobre a época. A primeira parte da gravação é falada, sendo uma narrativa pretérita na primeira pessoa do singular, e o fato da versão de Bethânia estar desligada do mundo de Palmares faz com que todo esse texto inicial associe-se à própria intérprete. A cantora baiana enuncia o texto com tal ênfase emocio- 
nal que sobressai a impressão dela estar discorrendo sobre si, rememorando sua própria trajetória pregressa. É como se, de cara, se personificasse naquilo que canta. $O$ que chama a atenção é que o recurso não é inédito; ao contrário, funciona exatamente como em sua recente interpretação histórica de Carcará. Assim como na canção do Show Opinião, aparece então, novamente, a nordestina marcada pela fome, pela seca e pela luta diária para a sobrevivência, que, no entanto, faz dessa tragédia sua grande força, como o próprio Carcará. A versão de Bethânia para Vivo num tempo de guerra já de início soa como uma retomada do espírito de Carcará: aquela ênfase na força, na coragem determinada do pássaro/sertanejo que vive em meio à tragédia da seca e que extrai vida da aridez da vida.

Quando Maria Bethânia fecha a primeira parte de Vivo num tempo de guerra com os versos "Minha voz não pode muito/ Mas gritar eu bem gritei!", renasce a diva sertaneja do Show Opinião, famélica e de aço - a ambivalência que tanto animou os jovens engajados de classe média que resistiam no campo da cultura pós-golpe. E Bethânia literalmente grita na passagem citada, ampliando a coincidência entre a intérprete e a personagem dos versos. Assim como em seu desempenho de Carcará, em que ela personifica o pássaro e se animaliza a medida que canta mimetizando, com movimentos ríspidos de pescoço, o Carcará e sua caçada². Ela era o Carcará. Bethânia interpreta essa força mítica sertaneja a ponto de confundir-se com ela. No Show Opinião era como se o tão idealizado povo de repente estivesse ali, enfim encontrado, para delírio da audiência. E deste procedimento hiperteatral decorreu o grande sucesso que Bethânia conquistou a partir de Carcará.

Paradoxalmente, poucos meses depois da estreia em Opinião e do sucesso em meio ao ambiente cultural de esquerda, ela assina com a RCA-Victor e grava seu primeiro compacto, ou seja, abrem-se as portas do mercado fonográfico para a heroína da resistência popular. O sucesso de vendas levou-a ao estúdio novamente para gravar o segundo compacto, com Vivo num tempo de guerra. Se, por um lado, a canção ganha autonomia nesta releitura toda própria, por outro a gravação ratifica um tipo de fetiche cultural típico da forma-mercadoria e é marcada por uma assinatura musical da intérprete. A retomada do recurso e da personagem cantora-sertaneja (fictícia) parece ser caso-pensado, formulação estratégica que já leva em conta, agora, os dese-

2. O registro do desempenho de Bethânia interpretando a canção no espetáculo encontra-se no filme O Desafio, de Paulo César Saraceni. 
jos do segmento que se quer alcançar. A canção então vem marcada por sua nova natureza, a de "símbolo vendável da revolução" (SCHWARZ, 2008, p. 64), em um lucrativo e paradoxal segmento de mercado, a canção de protesto.

Para muitos artistas de esquerda daquele momento, o sucesso atingido era atribuído a um desenvolvimento da consciência social, e os veículos de massificação - pautados pelo mercado - eram vistos como apenas imparciais possibilidades de alcances inimagináveis. Conforme afirma o historiador Marcos Napolitano, "o artista engajado tinha uma visão mais instrumental e neutra do mercado" (NAPOLITANO, 2001, p. 67). O controle precário dos meios de produção no período anterior, como a gravação independente de discos no CPC, editoração própria de livros e produção cinematográfica autônoma, era visto agora apenas como passos incertos e arcaicos diante do potencial incrível que se abria. A possibilidade de circulação que as gravadoras e a televisão apresentavam muitas vezes era defendida como a realização avançada do ideal de popularização tão perseguido. Mas se a posição pode ser a da adesão ingênua, também há um estranho entusiasmo com esse sucesso deflagrado, a ponto de as obras serem cada vez mais determinadas por critérios técnicos de mercado, como alcance, correspondência ao segmento-alvo, retorno de investimento etc., e isso jamais soar como um problema para os artistas progressistas do período.

Decerto nenhuma resposta é suficiente diante da complexidade da situação, a posição destes artistas não pode ser resumida em nenhuma fórmula fácil, do tipo: resistência heroica à ditadura; único caminho possível de seguir produzindo; ou mesmo adesão (ingenuamente) plena ao mundo da mercadoria. $O$ entrelaçamento disso tudo parece ser um dos signos do momento. Contudo, não é sempre igual, e a produção cultural começa a tender rapidamente para um dos lados dessa equação. Walter Benjamin, referindo-se à poesia engajada alemã em 1930, em um momento de refluxo e derrotas do proletariado, escreveu algo que serve bem ao período brasileiro: "Nunca ninguém se acomodou tão confortavelmente numa situação tão inconfortável” (BENJAMIN, 1985, p. 75).

O momento torna-se um quebra-cabeça de impasses, recuos e contradições. Em 1968, Augusto Boal encabeça o projeto da I Feira Paulista de Opinião, onde diversos autores, músicos etc. foram convidados a responder esteticamente a pergunta: “que pensa você do Brasil de hoje?". Mas foi no programa do ato artístico que o diretor realizou uma incisiva autocrítica à produção artística de esquerda no período. Em um texto intitulado Que pensa você da arte de 
esquerda? (1968), Boal afirma que o entusiasmo da cultura naqueles anos era equivocado e desmedido justamente pela impossibilidade de estabelecer trocas produtivas com os setores historicamente alijados da sociedade. $O$ cerne do argumento de Boal era a palavra de ordem: "o primeiro dever da esquerda é o de incluir o povo como interlocutor do diálogo teatral" (BOAL, 1968, p. 2). Afinal, diz o diretor, até o momento "o máximo que se tem conseguido fazer é incluir estudantes nas plateias", o que, apesar de admirável para "vitalizar o teatro" (BOAL, 1968, p. 3), não levava em consideração que o contato produtivo com as classes desfavorecidas tinha sido interrompido em 1964. Boal é o primeiro artista do período a afirmar isso. No mesmo texto ele diz:

Antigamente os Centros Populares de Cultura realizavam tarefas admiráveis no setor artístico e cultural: espetáculos, conferências, cursos, corais, alfabetização, cinema etc. Os reacionários, porém, escandalizaram-se com o fato de que também o povo gostava de teatro, gostava de aprender a ler etc. Os CPCs foram liquidados e os responsáveis por esse crime continuam no bem bom. (BOAL, 1968, p. 3)

Em um momento em que muitos de seus companheiros estavam defendendo a indústria cultural em formação ou inebriados com a "superação" propagandeada pela contracultura, ele reconheceu a cisão operada pelo golpe e assumiu uma posição que colocava a derrota nos cálculos do pensamento sobre teatro. Era preciso seguir marcando posição, mas também mostrar a impossibilidade de continuar, a ingenuidade do entusiasmo. No programa, afirma que o teatro que se fez desde 1964 foi "válido, atuante e funcional, politicamente correto, para frente etc.", mas emenda que "não se deve nunca esquecer que o verdadeiro interlocutor deste tipo de teatro é o povo, e o local escolhido para o diálogo deve ser a praça" (BOAL, 1968, p. 5).

Mesmo quando o teatro sucumbia ao fechamento do tempo, Boal tentou organizar uma autocrítica e fomentar uma nova atuação que tentava se conectar com as experiências passadas. Sua consciência do fracasso é inovadora e inédita. Contudo, sua determinação em "corrigir" os rumos do teatro de esquerda soa quixotesca e já bastante fora de tempo, quando as botas dos militares já cercavam qualquer possibilidade de teatro minimamente crítico e às vésperas do embrutecimento do regime. Ou, pior, sua inflexível autocrítica é dirigida a artistas de esquerda que agora combatiam deliberadamente as posições culturais anteriores em defesa da "Arte", com maiúscula, e das "possibilidades" da indústria de massa. Em meio a este torvelinho de ambivalências, 
foi o maior dos tropicalistas quem formulou, já na década de 1990, a trágica sentença que poderia ser a epígrafe destes anos esperançosos e sombrios:

Aqui tudo parece

Que era ainda construção

E já é ruína

(VELOSO, 1992).

\section{Referências bibliográficas}

BENJAMIN, W. Melancolia de Esquerda. In: Magia e técnica, arte e política.

São Paulo: Brasiliense, 1985.

BETHÂNIA, M. Carcará. RCA-Victor, 1965. LP-Compacto.

Vivo num tempo de guerra. RCA-Victor, 1965. LP-Compacto.

BOAL, A. Que pensa você da arte de esquerda? $8 \mathrm{f}$. Transcrição de uma cópia mimeografada do acervo de Augusto Boal, 1968. Disponível em: <https://institutoaugustoboal.files.wordpress.com/2012/11/que-pensa-vocc3aa-da-arte-de-esquerda-programa-da-feira.pdf>. Acesso em: 19 jun. 2015.

Teatro do oprimido e outras poéticas políticas. Rio de Janeiro: Civilização Brasileira, 1975.

BOAL, A.; GUARNIERI, G. Arena conta Zumbi. Revista de Teatro SBAT, Rio de Janeiro, n. 378, nov./dez. 1970.

BOAL, A. et al. Arena conta Zumbi. RGE, 1965. LP.

CAMPOS, C. A. Zumbi, Tiradentes. São Paulo: Perspectiva; EDUSP, 1988.

COSTA, A. et al. Opinião. Rio de Janeiro: Edições do Val, 1965.

COSTA, I. C. A hora do teatro épico no Brasil. São Paulo: Paz e Terra, 1996.

NAPOLITANO, M. Seguindo a canção. São Paulo: Annablume; Fapesp, 2001.

SCHWARZ, R. Cultura e política, 1964-1969. In:

O pai de família e outros

estudos. São Paulo: Companhia das Letras, 2008.

TOLEDO, Paulo Vinicius Bio. Impasses de um teatro periférico: as reflexões de Oduvaldo Vianna Filho sobre o teatro no Brasil entre 1958 e 1974. 2013. Dissertação (Mestrado em Teoria e Prática do Teatro) - Escola de Comunicações e Artes, Universidade de São Paulo, São Paulo.

VELOSO, C. Fora da ordem. In: Circuladô. Intérprete: Caetano Veloso. Rio de Janeiro: Universal, 1992. 39 min. 1 CD.

Recebido em 13/03/2015

Aprovado em 23/05/2015

Publicado em 30/06/201 